\title{
PERANCANGAN KAMPANYE SOSIAL TENTANG PENYU DI INDONESIA MELALUI TEKNIK HOLOGRAM 3D UNTUK DEWASA AWAL USIA 18 - 40 TAHUN
}

\author{
Youngky Kurniawan Wijaya ${ }^{1}$ \\ Muhammad Nasrulloh ${ }^{1}$ \\ Arjuna Bangsawan ${ }^{1}$ \\ Institut Informatika Indonesia, Surabaya ${ }^{1}$ \\ youngtjia@gmail.com
}

\begin{abstract}
Abstrak
Indonesia merupakan salah satu negara yang memiliki keanekaragaman satwa tertinggi di dunia dengan tingkat kepunahan jenis satwa yang cukup tinggi. Penyu adalah salah satu jenis satwa yang saat ini berada di ambang batas kepunahan. Dalam perancangan kampanye sosial ini, dibuat video hologram 3D tentang penyu yang bertujuan untuk dapat memberikan informasi tentang penyu secara unik dan inovatif dengan memanfaatkan teknologi piramida hologram. Konten yang terdapat pada video terbuat dari desain 3D sehingga dalam penerapannya sangat mendukung media piramida hologram tersebut. Perancangan ini bertujuan untuk mengenalkan dan memberikan informasi-informasi mengenai penyu yang terdapat di Indonesia agar khalayak dapat sadar akan pentingnya kehidupan penyu dan dapat ikut ambil bagian dalam upaya penyelamatan penyu dari ancaman kepunahan. Pada akhir perancangan didapatkan hasil bahwa dalam merancang piramida hologram terdapat beberapa pertimbangan-pertimbangan yang perlu dipikirkan secara matang dalam mewujudkannya. Pertimbangan-pertimbangan tersebut antara lain, kondisi cahaya ruangan, jenis dan ketebalan material yang digunakan, sudut kemiringan, piramida hologram, serta media pemancarnya.
\end{abstract}

Katakunci: Penyu, Animasi, Hologram, Konservasi

\begin{abstract}
Indonesia is one of the countries that has the highest animal diversity in the world with a high level of extinction of animal species. Sea turtles are one type of animal that is currently at the threshold of extinction. In this social campaign, a 3D hologram video about sea turtles was made which aims to be able to provide unique and innovative information about sea turtles by utilizing holographic pyramid technology. The content in the video is made of $3 D$ design so
\end{abstract}


that is very supports the hologram pyramid media. This design aims to introduce and provide information about sea turtles found in Indonesia so that the public can be aware of the importance of turtle life and can take part in efforts to save turtles from the threat of extinction. At the end of the design, it was found that in designing the hologram pyramid there were several considerations that needed to be considered carefully to realize it perfectly. These considerations are, among others, the condition of the room's light, the type and thickness of the material used, the slope angle, the hologram pyramid, and the transmitting media.

Keywords: Sea turtle, Animation, Holographic, Conservation.

\section{PENDAHULUAN}

Menurut ProFauna (2017), penyu adalah salah satu satwa laut yang saat ini populasinya sudah memprihatinkan. Indonesia adalah rumah bagi enam dari tujuh spesies penyu di dunia. Jenis penyu yang ada di Indonesia adalah penyu hijau, penyu sisik, penyu lekang, penyu tempayan, penyu pipih, dan penyu belimbing. Menurut IUCN, enam spesies penyu laut tersebut tercantum dalam daftar merah spesies yang terancam punah sebagai yang rentan, terancam, dan sangat terancam. Ancaman terhadap penyu adalah perdagangan baik dalam bentuk daging, telur ataupun bagian tubuhnya. Pencemaran laut oleh minyak dan sampah plastik juga menjadi ancaman bagi kelestarian penyu. Tim Profauna dan banyak pihak-pihak terkait sudah pernah melakukan banyak sosialisasi. Tetapi sosialisasi-sosialisasi tersebut seakan-akan kurang memiliki efek yang signifikan terhadap masyarakat akan pentingnya keberadaan penyu.

Berdasarkan fenomena dan permasalahan tersebut, maka peneliti merancang video kampanye sosial sebagai salah satu contoh program yang informatif terhadap masyarakat tentang penyu. Perancangan kampanye sosial ini dibuat dengan menggunakan media hologram. Hologram menampilkan objek 3D yang dapat mewakili objek aslinya, yang dalam konteks ini adalah penyu. Media Hologram dipilih karena kampanye sosial ini ditempatkan di tempat keramaian dan terbuka, sehingga dapat dinikmati oleh target audience dari sudut pandang 360 derajat secara horizontal. Diharapkan masyarakat yang ada di sekitar dapat lebih peka untuk ikut berpartisipasi dalam melestarikan penyu sehingga populasi penyu tetap 
terjaga. Target audience yang dipilih pada perancangan kampanye sosial ini adalah dewasa awal usia 18-40 tahun. Pemilihan usia ini dikarenakan pada usia ini adalah masa beralihnya pandangan egosentris menjadi sikap yang empati. Selain itu, masa dewasa awal adalah masa dimana seseorang beradaptasi dan lebih peka dengan lingkungan sekitar (Hurlock, 1986).

\section{METODE PENELITIAN}

Merujuk pada fenomena masalah yang dialami oleh spesies penyu yang semakin terancam punah, oleh karena itu dibutuhkan sebuah kampanye sosial. Dalam proses pengumpulan data menggunakan beberapa metode yaitu menggunakan metode pengumpulan data primer dan sekunder.

Pengumpulan data Primer adalah terdiri dari wawancara dan observasi, wawancara yang dilakukan untuk dapat mengetahui lebih lanjut perkembangan penyu di Indonesia, dan untuk observasi dilakukan untuk lebih mengetahui beberapa media yang pernah digunakan sebagai media kampanye dengan tema yang berbeda sebagai media komparator.

Pengumpulan data Sekunder meliputi pengumpulan data melalui jurnal, artikel dan buku ilmiah untuk menunjang proses penelitian dan mendapatkan data tentang objek penelitian dan media yang sesuai dan dapat menarik perhatian bagi target audience, serta dapat menjaga agar tetap informatif dalam penyampaian pesan.

\section{HASIL DAN PEMBAHASAN}

Perancangan kampanye sosial ini dibuat dengan menggunakan media hologram karena memiliki sudut pandang 360 derajat secara horizontal. Namun secara teknis media hologram yang digunakan masih harus menggunakan media penangkap gambar, dalam penelitian ini menggunakan media akrilik dengan bentukan piramida agar dapat menangkap dan memantulkan gambar dari LCD atau proyektor. 
Berikut adalah tampilan media hologam dengan menggunakan media akrilik.

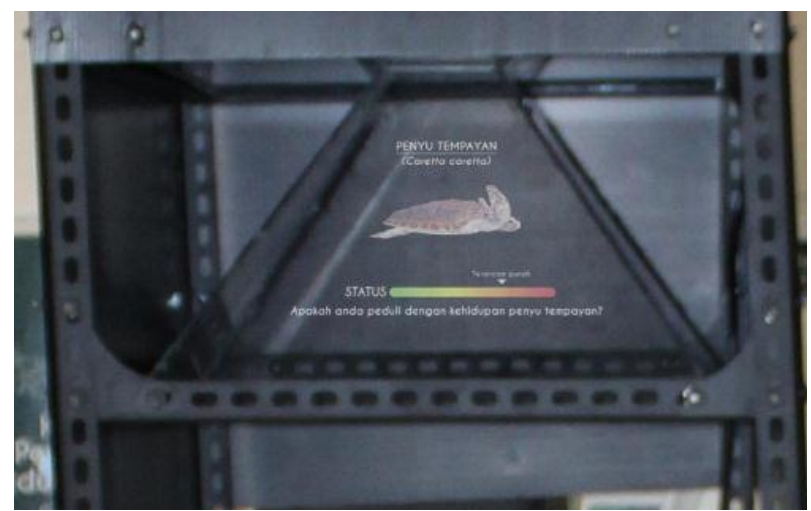

Gambar 1. Piramida Hologram

Sumber: Dokumentasi Penulis

Model 3D dibuat dengan konsep realistik sehingga dapat mewakili dan memberikan gambaran kepada khalayak tentang hewan penyu yang ada di perairan Indonesia. Selain itu model 3D dianimasikan agar terlihat lebih hidup.

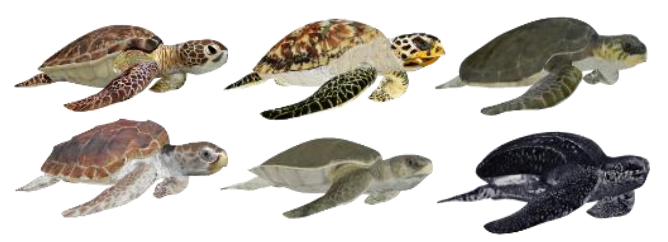

Gambar 2. Model 3D Penyu

Sumber: Dokumentasi Penulis

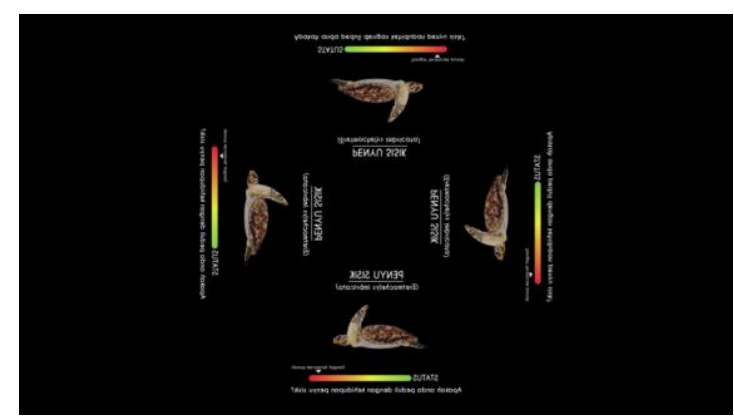

Gambar 3. Tampilan Piramida Hologram

Sumber: Dokumentasi Penulis 


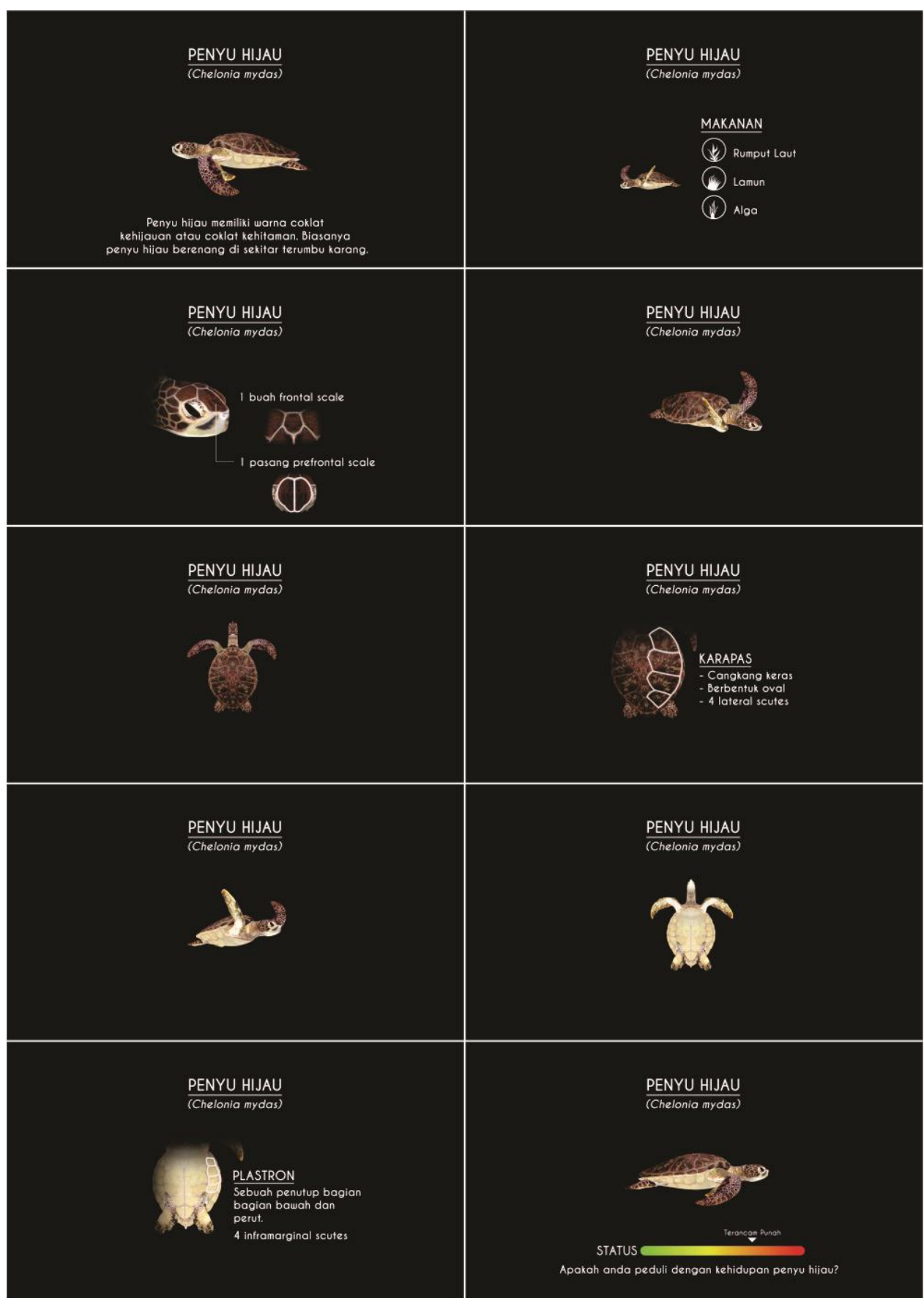

Gambar 4. Video Animasi

Sumber: Dokumentasi Penulis

Media pendukung terdiri dari Pin, Cutting Sticker, Poster, Kaos, Buku panduan, serta mini hologram dirancang bertujuan untuk mendukung dan 
menambahkan nilai lebih pada kampanye sosial penyu di Indonesia ini. Berikut adalah beberapa media pendukung:
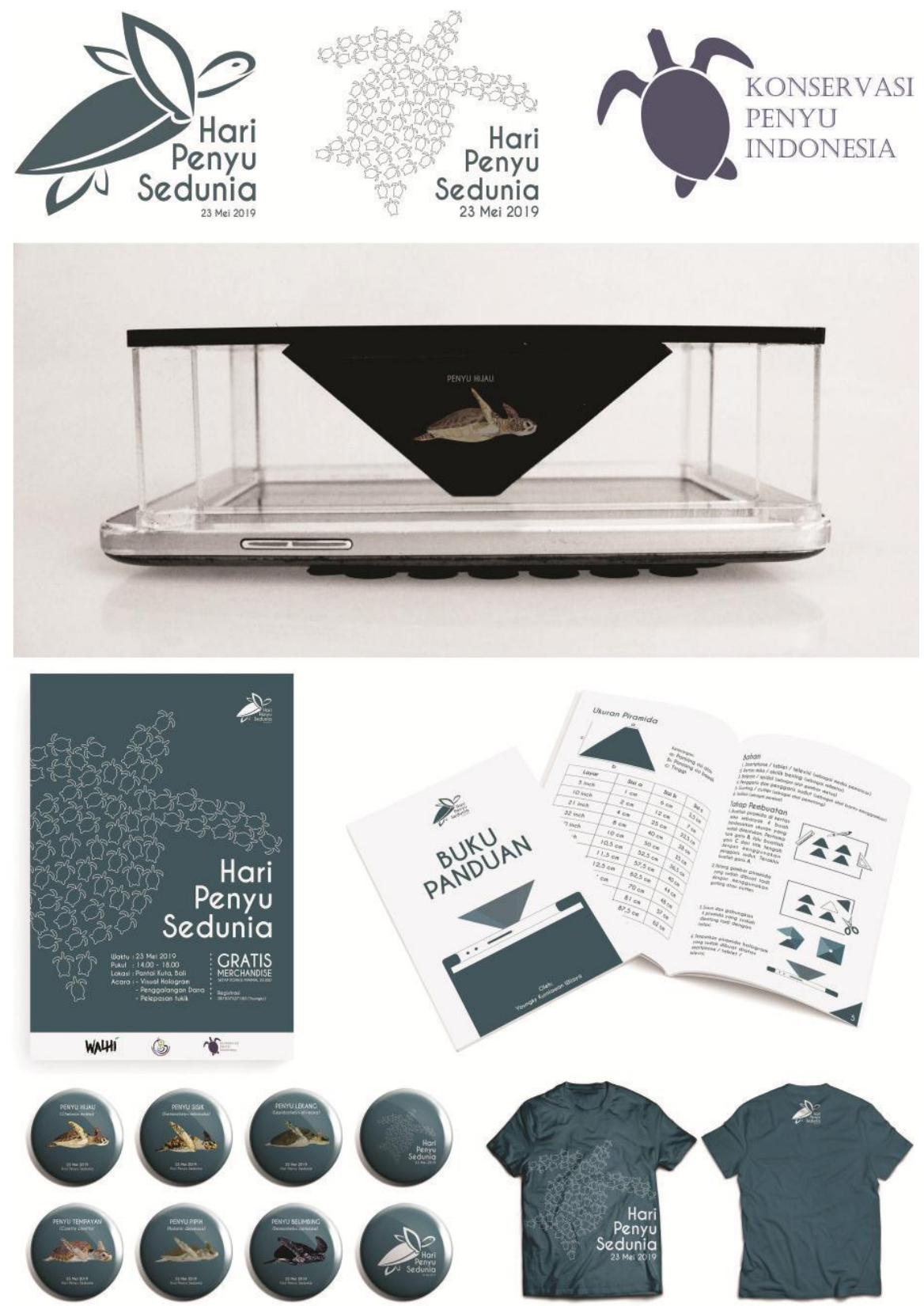

Gambar 5. Media Pendukung

Sumber: Dokumentasi Penulis 


\section{SIMPULAN DAN SARAN}

\section{Simpulan}

Terdapat beberapa hal yang harus dijadikan pertimbangan dalam merancang piramida hologram ini. Pertimbangan-pertimbangan tersebut antara lain, kondisi ruangan, jenis dan ketebalan akrilik yang digunakan, sudut kemiringan, dan media pemancarnya. Pertimbangan-pertimbangan tersebut bertujuan agar hologram yang ditayangkan dapat terlihat dengan jelas dan terang saat dipantulkan oleh piramida hologram. Selain itu, perlu dilakukan tes uji coba terlebih dahulu agar segala kemungkinan terburuk bisa teratasi dengan optimal. Pada perancangan tugas akhir ini, penulis tidak melakukan tes uji coba terlebih dahulu. Sehingga saat dieksekusi, penulis menemui beberapa kendala dan hambatan seperti hologram pantulan tidak terlihat begitu jelas sehingga hasil yang didapatkan tidak sesuai dengan ekspektasi.

\section{Saran}

Saran terakhir yang diberikan penulis kepada mahasiswa dan pembaca yang ingin mencoba membuat karya yang sama diperlukan ketelitian dalam mencari referensi yang tepat untuk dijadikan pertimbangan pada piramida hologram yang akan dibuat. Deiperlukan tes uji coba terlebih dahulu agar segala kemungkinan terburuk dan kesalahan bisa diperbaiki sebelum hari eksekusi.

\section{DAFTAR PUSTAKA}

Cangara, Hafied. 2011. Pengantar ilmu komunikasi. Jakarta: PT Raja Grafindo. Persada

Hurlock, Elizabeth B, 1986. Developmental Psychology. 3rd Ed, New Delhi: McGraw Hill, Inc.

Kandarika, M. (2017). Mengetahui Lebih Dalam Mengenai Teknologi Hologram [Gambar dan Artikel]. Diakses dari http://www.archivioguerrapolitica.org/2017/10/24/mengetahui-lebih-dalammengenai-teknologi-hologram/ Pada tanggal 1 November 2017 pukul 12.19 WIB.

Megantara, M. W. (2009). Perancangan Interior Sea Turtle Center Dengan Konsep Adventural Journey. Diakses dari 
repository.maranatha.edu/629/Pada tanggal 16 November 2017 pukul 19.31 WIB

ProFauna. 2017. Tentang Penyu Indonesia. Diakses pada tanggal 18 November 2017 dari http://www.profauna.net/id/kampanye-penyu/tentang-penyuindonesia. 